\title{
Research on two-stage allocation optimization technology of power grid operation and maintenance cost input considering asset scale status and efficiency fairness
}

\author{
$\mathrm{Na} \mathrm{Yu}{ }^{1}$, Shiyan $\mathrm{Mei}^{2}$, Ming $\mathrm{Chen}^{2}$, Kai $\mathrm{Hou}^{2}$, Chao $\mathrm{Chen}^{3 *}$ \\ ${ }^{1}$ Guangdong Power Grid Co., Ltd., Guangzhou City, Guangdong, 510000, China \\ ${ }^{2}$ Power Grid Planning \& Research Center, Guangdong Power Grid Co., Ltd., Guangzhou City, Guangdong, 510000, China \\ ${ }^{3}$ School of Economics and Management, North China Electric Power University, Beijing 102206, China
}

\begin{abstract}
The current complex internal and external situation puts forward higher requirements for the precise investment of funds for power grid companies. This paper proposes a two-stage operation and maintenance cost input optimization allocation technology based on comprehensive evaluation and Gini coefficient adjustment. This technology firstly identifies the influencing factors of operation and maintenance cost input, and combines the result of factor identification to construct an evaluation index system based on asset status and scale attributes. Through comprehensive evaluation and collection of index-related data, it determines the initial distribution coefficients and initial distribution coefficients of related enterprises based on the entropy weight method. Then combined with the principle of Gini coefficient, optimize the initial allocation plan to obtain the final investment allocation quota. This paper conducts empirical analysis with 10 companies as the research object, and the results show that the model can provide theoretical support and method reference for reasonable investment and reasonable decision-making of operation and maintenance costs of power grid companies under the requirements of precise investment management and control.
\end{abstract}

\section{Introduction}

Operation and maintenance investment scale is closely related to asset status, asset scale and other factors. In order to ensure the reasonable allocation of operation and maintenance investment, a scientific decision-making basis must be determined. Literature [1] combines principal component analysis to quantitatively analyze the factors affecting operation and maintenance investment, and perform regression analysis on grid operation and maintenance costs and principal components; literature [2] combines actual extraction of the main factors affecting distribution network operation and maintenance costs as input variables for the prediction of operation and maintenance investment scale; Literature [3-4] established a distribution network investment distribution model, which realized the reasonable distribution of distribution network funds among different regions; proposed a method of prioritizing distribution network construction projects, and realized the integration of distribution network construction projects. Evaluation and scientific ranking. Literature [5] evaluates and analyzes the investment data over the years, based on The status quo and load growth are estimated for the scale of distribution networks in various regions and therefore used as the main basis for investment allocation, considering the core elements of investment allocation from different perspectives. The above-mentioned documents have certain support for improving the scientificity of the operation and maintenance cost input allocation of power grid enterprises in terms of improving the operation and maintenance investment decision-making, the operation efficiency level and the scientific investment strategy, but the research on the input allocation method is still insufficient.

\section{The main idea of the technical method The traditional operation and maintenance}

Therefore, based on the Gini coefficient theory, this paper proposes a two-stage decision-making optimization technology that comprehensively considers the input effect, and weighs the actual conditions of each region in combination with different dimensions such as economy and security for scientific distribution, which is conducive to increasing the cost of grid operation and maintenance Rationality, to ensure the reasonable development of power grid operation and maintenance in

*Corresponding author’s e-mail: 1182306191@ncepu.edu.cn 
various regions, and to improve the efficiency of capital utilization and output effects. The specific research ideas are shown in Figure 1 below:

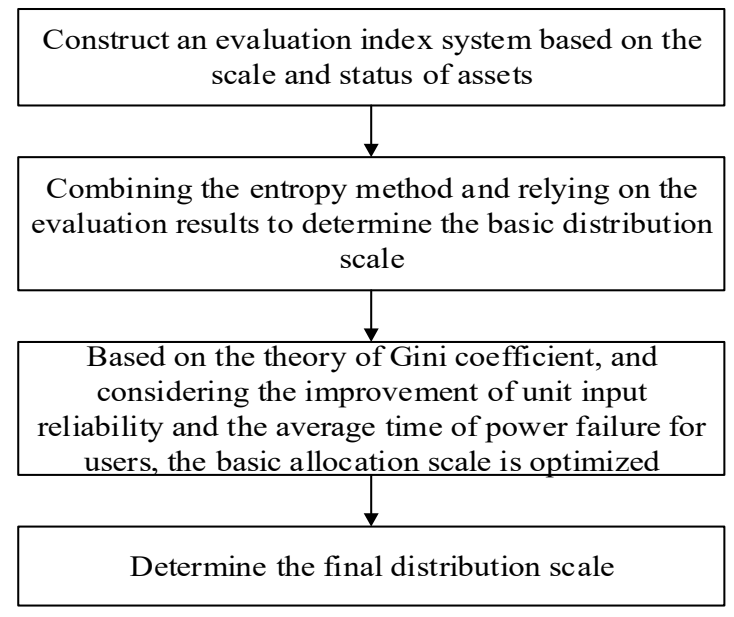

Figure 1. The main idea of optimization technology.

\section{Research on optimization technology of power grid operation and maintenance cost input allocation}

\subsection{Initial allocation model construction}

\subsubsection{Identification of factors affecting grid operation and maintenance costs}

First, comprehensively identify the influencing factors of the cost of grid operation and maintenance, and identify the total fixed assets, power outage plan, average operating life of equipment, depreciation level, topography, meteorological environment, economic level, substation type, equipment failure rate, equipment defect Influencing factors such as rate rate. Combining actual experience and expert opinions, the identified influencing factors were eliminated and sorted out, redundant factors were eliminated, and four more important influencing factors were screened out: total fixed assets, average operating life of equipment, equipment defect rate, and equipment failure rate.

\subsubsection{Construction of a model for the allocation of power grid operation and maintenance costs}

(1) Construction of evaluation index system Combining the above-mentioned influencing factor identification results, a comprehensive evaluation method is adopted to construct the initial allocation model and finally a comprehensive evaluation index system. details as follows:

Table 1. Comprehensive evaluation index system.

\begin{tabular}{cc}
\hline $\begin{array}{c}\text { Serial } \\
\text { number }\end{array}$ & index \\
\hline 1 & Total fixed assets \\
2 & Average operating life of equipment \\
\hline
\end{tabular}

\begin{tabular}{ll}
\hline 3 & Equipment failure rate \\
4 & Equipment defect rate \\
\hline
\end{tabular}

(2) Determination of index weight The entropy method is used to determine the weights of related indicators, and the specific calculation methods are as follows:

1) First, normalize the value of index $c_{j}$ corresponding to the allocated area:

$$
m_{i j}=p_{i j} / \sum_{i=1}^{k} p_{i j}
$$

2) Then calculate the information entropy $e_{j}$ of index $c_{j}$ :

$$
e_{j}=-\left(\sum_{i=1}^{k} m_{i j} \ln m_{i j}\right) / \ln n
$$

In the formula: $\mathrm{n}$ is the number of enterprises, if $m_{i j}=0$, then $m_{i j} \ln m_{i j}=0$. Finally, calculate the weight $c_{j}$ of each index.

$$
c_{j}=\left(1-e_{j}\right) / \sum_{j=1}^{9}\left(1-e_{j}\right)
$$

3) Calculate the weight $w_{j}$ of each evaluation index:

$$
w_{j}=b_{m} * c_{j}
$$

4) Combined with relevant data, conduct a comprehensive evaluation for each company to obtain the score of each company; weighted average the evaluation scores to obtain the distribution ratio of the operation and maintenance cost of each power supply company; the calculation formula is as follows:

$$
k_{i}=\frac{w_{i} z_{i}}{\sum_{i=1}^{i} w_{i} z_{i}}
$$

After clarifying the initial investment allocation coefficient of each enterprise, combined with the total investment scale of operation and maintenance costs in the next year, the initial allocation amount of the enterprise can be determined. The specific calculation formula is as follows:

$$
T_{i}=S_{i} * k_{i}
$$

\subsection{Initial plan evaluation and plan optimization based on Gini coefficient theory}

Taking the minimum sum of Gini coefficients corresponding to all enterprises as the objective function, and taking the reduction ratio of each enterprise's operation and maintenance cost input as the decision variable, a single-objective multi-constraint linear 
programming model is constructed to further optimize and adjust the initial investment allocation plan.

\section{Empirical analysis}

10 county-level power supply companies belonging to the $\mathrm{Z}$ city-level power company are selected as the research objects, combined with optimization technology methods, optimized and analyzed for the operation and maintenance cost investment scale of the power company in the next year. details as follows:

(1) Basic data collection In the past three years, the scale of investment in power grid operation and maintenance costs of the Z City Power Company has increased year by year. It is estimated that the scale of investment in operation and maintenance costs of 10 county-level power supply companies in 2021 will be 30 million yuan. At the same time, through the investigation and sorting of the corresponding indicator data, the actual collected data are as follows:

Table 2. Table of original statistics.

\begin{tabular}{|c|c|c|c|c|c|c|c|c|}
\hline $\begin{array}{c}\text { Serial } \\
\text { number }\end{array}$ & $\begin{array}{l}\text { company } \\
\text { name }\end{array}$ & $\begin{array}{l}\text { Total fixed } \\
\text { assets }\end{array}$ & $\begin{array}{l}\text { Average } \\
\text { operating life } \\
\text { of equipment }\end{array}$ & $\begin{array}{l}\text { Equipment } \\
\text { failure rate }\end{array}$ & $\begin{array}{l}\text { Equipment } \\
\text { defect rate }\end{array}$ & $\begin{array}{c}\text { Unit input } \\
\text { power supply } \\
\text { reliability } \\
\text { improvement } \\
\text { level }\end{array}$ & $\begin{array}{l}\text { Unit input user } \\
\text { power outage } \\
\text { time reduction } \\
\text { level }\end{array}$ & $\begin{array}{c}\text { Operation } \\
\text { and } \\
\text { maintenance } \\
\text { cost }\end{array}$ \\
\hline & & $\begin{array}{c}100 \text { million } \\
\text { yuan }\end{array}$ & year & $\begin{array}{l}\text { Times/100 } \\
\text { units/year }\end{array}$ & $\begin{array}{l}\text { Times/100 } \\
\text { units/year }\end{array}$ & $\begin{array}{c}\% / \text { Ten thousand } \\
\text { yuan }\end{array}$ & $\begin{array}{c}\min / 10,000 \\
\text { yuan }\end{array}$ & $\begin{array}{c}\text { Ten thousand } \\
\text { yuan }\end{array}$ \\
\hline 1 & A & 0.23 & 12.43 & 4.2 & 4.6 & 0.000758 & 0.0996 & 201.51 \\
\hline 2 & B & 0.16 & 10.74 & 6.2 & 3.8 & 0.001582 & 0.0843 & 256 \\
\hline 3 & $\mathrm{C}$ & 0.13 & 9.94 & 3.4 & 5.2 & 0.00113 & 0.0712 & 234.17 \\
\hline 4 & $\mathrm{D}$ & 0.18 & 8.43 & 3.8 & 4.1 & 0.000611 & 0.0328 & 189.37 \\
\hline 5 & $\mathrm{E}$ & 0.17 & 10.41 & 5.3 & 6.8 & 0.000138 & 0.0283 & 282.43 \\
\hline 6 & $\mathrm{~F}$ & 0.14 & 9.97 & 3.2 & 4.9 & 0.000447 & 0.0276 & 212.92 \\
\hline 7 & G & 0.17 & 10.43 & 4.6 & 3.1 & 0.000212 & 0.0155 & 390.71 \\
\hline 8 & $\mathrm{H}$ & 0.15 & 9.53 & 4.2 & 4.1 & 0.000148 & 0.0211 & 250.56 \\
\hline 9 & I & 0.13 & 10.12 & 6.8 & 4.9 & 0.000148 & 0.0151 & 284.7 \\
\hline 10 & $\mathrm{~J}$ & 0.18 & 11.54 & 5.1 & 3.3 & 0.000264 & 0.0147 & 324.23 \\
\hline
\end{tabular}

(2) Initial investment allocation plan Combined with the construction of the above distribution optimization system, through normalization, the entropy method is used to calculate the standard value and weight of each index.

(3) Adjust the investment allocation plan Grid operation and maintenance investment mainly solves the problem of equipment operation and ensures the safe and stable operation of the grid. Therefore, according to the Gini coefficient theory, the reliability improvement level of unit input and the reduction level of power outage time per unit input user are selected as control indicators, and the index values of each enterprise unit are used as the control indicators.

Based on the analysis of the current internal and external operating situation of power grid companies, and expert experience judgment as the main method, the unit input reliability improvement level index weight is positioned as 0.6 , and the unit input user outage time reduction level index weight is set as 0.4. Multiply the initial Gini coefficient of each control index by their respective weights, and add them to get the initial total Gini coefficient. According to calculations, the initial total Gini coefficient is 0.3621 . According to the above calculation beam conditions and boundary range, Set the adjustment of each company's operation and maintenance cost input to be controlled within $\pm 15 \%$, and the total investment within $\pm 5 \%$. The optimized Gini coefficient is 0.2571 , which is relatively average. It can be concluded that the operation and maintenance of each company in
2021 The cost investment optimization plan is shown in the following table 3 :

Table 3. Optimized input allocation table.

\begin{tabular}{cccc}
\hline $\begin{array}{c}\text { Serial } \\
\text { number }\end{array}$ & $\begin{array}{c}\text { company } \\
\text { name }\end{array}$ & $\begin{array}{c}\text { Initial allocation } \\
\text { plan }\end{array}$ & $\begin{array}{c}\text { Optimize the } \\
\text { allocation plan }\end{array}$ \\
\hline 1 & $\mathrm{~A}$ & $10.84 \%$ & $11.24 \%$ \\
2 & $\mathrm{~B}$ & $10.70 \%$ & $16.64 \%$ \\
3 & $\mathrm{C}$ & $9.07 \%$ & $14.05 \%$ \\
4 & $\mathrm{D}$ & $8.94 \%$ & $8.93 \%$ \\
5 & $\mathrm{E}$ & $12.01 \%$ & $8.02 \%$ \\
6 & $\mathrm{~F}$ & $8.85 \%$ & $8.54 \%$ \\
7 & $\mathrm{G}$ & $9.14 \%$ & $8.14 \%$ \\
8 & $\mathrm{H}$ & $9.10 \%$ & $8.10 \%$ \\
9 & $\mathrm{I}$ & $11.40 \%$ & $7.39 \%$ \\
10 & $\mathrm{~J}$ & $9.95 \%$ & $8.95 \%$ \\
\hline
\end{tabular}

As can be seen from the above table, after optimization, the allocation scale of operation and maintenance input of each enterprise has been adjusted. On the one hand, the overall asset scale status of different units is considered, and on the other hand, the input scale of the operation and maintenance cost is combined with the input-output effect. Optimized adjustment to ensure the fairness of capital investment efficiency. 


\section{5 conclusion}

For a long time, there has not been a clear quantitative analysis standard and basis for how the grid operation and maintenance cost investment scale should be allocated among various regional companies, and there is a lack of theoretical support. This paper proposes a two-stage allocation method for grid operation and maintenance cost input considering asset scale status and efficiency fairness. This method firstly determines the initial allocation of each enterprise based on the comprehensive evaluation of the scale and status of power grid assets; then introduces the concept of Gini coefficient into the allocation plan for the operation and maintenance cost of the power grid company, and establishes a distribution optimization model based on the Gini coefficient for fairness Evaluation and optimization of allocation quotas to improve the ability to optimize resource allocation and comprehensive efficiency. With the continuous improvement of the level of refinement of business development, deepening the optimization of operation and maintenance investment decision management, adapting to the current reform and development requirements and improving quality and efficiency development needs, achieving precise investment and reasonable allocation, and improving the ability to optimize resource allocation and comprehensive efficiency.

\section{References}

1. Zhu Yongjuan. Research on optimization method of power grid investment allocation based on regional development[J]. Electric Power and Energy, 2016, 37(06): 704-708.

2. Li Meng, Li Xiaodong. Research on the investment allocation model of power grid companies based on investment capability[J]. Northeast Electric Power Technology, 2016, 37(01): 19-23+33.

3. Cui Wenting, Liu Hong, Yang Weihong, Wang Xuyang, Ji Shiyu. Research on distribution network investment allocation and project optimization [J]. China Electric Power, 2015, 48(11): 149-154.

4. Wang Yingxiang, Fang Suicun, Zhang Ji, Ge Ting, Chen Yanbo. Research on Distribution Network Investment Decision System[J]. Wisdom Electric Power, 2019, 47(02): 56-62.

5. Li Ke, Fu Guanghui, Tian Chunzheng, Yu Haozheng, Li Cheng. Distribution network investment allocation method and project optimization based on historical investment results $[\mathrm{J}]$. Computing Technology and Automation, 2019, 38(03): 33-38. [6] Yu Song, Wu Yanlin, Wang Zhuding, Zhang Man. Model strategy for distribution network investment allocation [J]. Power Grid and Clean Energy, 2017, 33(12): 28-36. 